\title{
Clinicophysiological, haematobiochemical and haemodynamic effect of propofol and ketamine with dexmedetomidine in urolithic goats
}

\author{
Rohit Kumar $^{1}$, P. Kinjavdekar ${ }^{1}$, Amarpal ${ }^{1}$, H. P. Aithal ${ }^{1}$, A. M. Pawde ${ }^{1}$, A. Kumar ${ }^{2}$, J. Singh ${ }^{1}$, S. Khattri ${ }^{1}$ and D. N. Madhu ${ }^{1}$ \\ 1. Division of Surgery, Indian Veterinary Research Institute, Izatnagar - 243122, Uttar Pradesh, India; \\ 2. Division of Animal Genetics, Indian Veterinary Research Institute, Izatnagar - 243122, Uttar Pradesh, India. \\ Corresponding author: Rohit Kumar, email: drrohits.singh@gmail.com \\ PK:p.kinjavdekar@rediffmail.com, A: dramarpal@gmail.com,HPA:hpaithal@rediffmail.com, \\ AMP: abhimp@rediffmail.com,AK:vetamitchandan07@gmail.com, JS:vet_jasmeetsingh@rediffmail.com, \\ SK:siddharthkhattri@gmail.com, DNM:madhu63vsr@gmail.com \\ Received: 09-04-2014, Revised: 17-06-2014, Accepted: 24-06-2014, Published online: 05-08-2014
}

doi: 10.14202/vetworld.2014.566-573 How to cite this article: Kumar R, Kinjavdekar P, Amarpal, Aithal HP, Pawde AM, Kumar A, Singh J, Khattri S and Madhu DN (2014) Clinicophysiological, haematobiochemical and haemodynamic effect of propofol and ketamine with dexmedetomidine in urolithic goats, Veterinary World 7(8): 566-573.

\begin{abstract}
Aim: To compare clinicophysiological, haematobiochemical and haemodynamic effects of propofol and ketamine total intravenous anaesthesia (TIVA) with dexmedetomidine in uraemic goats.

Materials and Methods: Prospective, randomized clinical trials were performed in sixteen clinical cases of urolithiasis in goats. After sedation with dexmedetomidine $(2.5 \mu \mathrm{g} / \mathrm{kg}$ body wt $)$ anaesthesia was induced and maintained with propofol in group Dexmedetomidine+Propofol (DP) and with ketamine in group Dexmedetomidine+Ketamine (DK). Continuous intravenous infusion (CII) was used with respective drug for maintenance of anaesthesia. Infusion rate was adjusted in response to positive reactions to surgical nociceptive stimulation performed during tube cystostomy procedure or by observing pedal reflex after completion of surgery till discontinuation of anaesthesia. Clinicophysiological, haematobiochemical and haemodynamic parameters were measured before treatment (baseline), after sedation and during anaesthesia. Two-way analysis of variance with repeated measurements was used to analyze the data.

Results: Mean values of equipotent induction and maintenance dose in group DP were $(2.50 \pm 0.37 \mathrm{mg} / \mathrm{kg}$ and $0.15 \pm 0.03$ $\mathrm{mg} / \mathrm{kg} / \mathrm{min})$ significantly lower $(9.85 \pm 0.85 \mathrm{mg} / \mathrm{kg}$ and $0.54 \pm 0.07 \mathrm{mg} / \mathrm{kg} / \mathrm{min})$ than DK. Heart rate decreased significantly $(\mathrm{p}<0.05)$ up to the end of observation period after induction of anaesthesia with propofol. However, after induction of anaesthesia with ketamine HR improved at $15 \mathrm{~min}$ and onwards. Mean arterial pressure (MAP) decreased significantly $(\mathrm{p}<0.05)$ at 15 min onwards up to the end of observation period in DP group. However, in DK group, MAP decreased nonsignificantly $(p>0.05)$ up to the end of the observation period after induction of anaesthesia with ketamine.
\end{abstract}

Conclusion: Both drug combinations are suitable for induction and maintenance anaesthesia for one hour, with good analgesia and haemodynamic stability. However, treatment DP produced excellent sedation and muscle relaxation.

Keywords: dexmedetomidine, goats, ketamine, propofol.

\section{Introduction}

Urolithiasis is a common clinical condition of almost all domestic animals but higher incidence has been recorded in bovine and caprine [1]. Several anaesthetic techniques with different drugs have been used for the management of urolithiasis. Total intravenous anaesthesia (TIVA) for short procedures seems to carry a lower risk of intraanaesthetic death than volatile agents [2]. In veterinary practice, intravenous anaesthetic drugs are commonly used as induction agents to facilitate endotracheal intubation, whilst inhalation anaesthetic agents form the foundation for maintenance of general anaesthesia [3]. Volatile anaesthetics cause dosedependent cardiopulmonary depression and hypoventilation. Blood pressure is preserved better during infusion of injectable drugs but this does not always reflect overall cardiopulmonary function [4].

Dexmedetomidine, a newer $\alpha_{2}$-agonist, reduces

Copyright: The authors. This article is an open access article licensed under the terms of the Creative Commons Attribution License (http://creativecommons.org/licenses/by/2.0) which permits unrestricted use, distribution and reproduction in any medium, provided the work is properly cited. the dose requirements of opioids and anaesthetic agents and attenuates the haemodynamic responses to tracheal intubation and surgical stimuli and has been studied in goats, however, its clinical effects are presumed to be comparable with those of racemic medetomidine [5]. Intravenous anaesthetic agents used for maintenance of anaesthesia in animals include propofol and ketamine [6] as continuous intravenous infusion. Propofol, a short-acting hypnotic agent, is usually injected as a single bolus for induction to allow intubation and initiation of inhalant anaesthesia, a popular technique in small animals [7]. Propofol has been investigated as intravenous anaesthetic in sheep [8], goats [9] and buffaloes [6]. Propofol has been accepted as the most useful agent for maintenance of anaesthesia, either by intermittent bolus infusion or continuous intravenous infusion [6]. Ketamine has been used for maintenance of anaesthesia, either by intermittent bolus infusion or continuous intravenous infusion [6].

There is limited literature regarding the use of dexmedetomidine in goats, further, these drugs along with propofol and ketamine has not been used in uraemic 
animals. The present study was therefore, designed to compare the suitability of propofol and ketamine anaesthesia using two different preanaesthetic protocols.

\section{Materials and Methods}

Ethical approval: The present study was approved by the Institutional Animal Ethics Committee and has therefore, been performed in accordance with the ethical standards laid down in the 1964. Declaration of Helsinki and its later amendments. Written and informed consent was obtained from the owners prior to subjecting the animals to the study.

Animals: Sixteen male goats suffering from urethral obstruction brought to the Polyclinic, Division of Surgery, Indian Veterinary Research Institute, Izatnagar 243 122, India were randomly divided into groups DP (Dexmedetomidine+Propofol) and DK (Dexmedetomidine+Ketamine) containing eight animals in each group.

Study design: A prospective, randomized clinical trial was performed on sixteen ASA (American Society of Anesthesiologists) physical status II or III goats, which were scheduled for emergency tube cystostomy. Animals were excluded from the study if they were classified as ASA IV or greater, if there were contraindications with the drug protocol, or if they were excessively nervous or aggressive for which the sedation protocol would be inappropriate. All animals in present study completed clinical trial without any side effect. Before surgery, complete history of the animal including breed, age, history of castration (if castrated), duration of illness, common feeds provided to the animal, concentrate and previous treatment given to the animal were recorded. All the 16 animals in the study were in the age of 2 to 6 months. Clinical examination of the animal included general condition of the animal, color of mucous membrane, heart rate, respiratory rate and rectal temperature. Other signs like oliguria, anuria, stranguria, haematuria, if present, were also recorded. Diagnosis of the status of urinary bladder was carried out by manual palpation, abdominocentesis, and radiography/ultrasonography as per the requirement of the case. Fluid therapy was administered as soon as possible in cases of urinary bladder rupture.

Techniques of anaesthesia and surgery: Animals were randomly allocated to receive dexmedetomidine (2.5 $\mu \mathrm{g} / \mathrm{kg}$ body wt) as premedication and after 10 minutes induction were achieved by intravenous administration of $1 \%$ propofol (DP) and ketamine (DK) till effect. Anaesthesia was maintained with Continuous Intravenous Infusion (CII) of propofol (DP) or ketamine (DK) in respective groups. Administration of equipotent dose for propofol or ketamine during induction of anaesthesia, were determined by observing the abolition of pedal reflex. However, during maintenance anaesthesia continuous infusion was adjusted in response to positive reactions to surgical nociceptive stimulation performed during tube cystostomy. After clipping and aseptic preparation of the ventral abdomen, a 1 to 2 inch paramedian approach was made $2-4 \mathrm{~cm}$ lateral to the prepuce, halfway between the base of scrotum and preputial orifice. Free abdominal fluid was aspirated slowly using active suction. The bladder was identified with the help of index finger and a Foley's catheter of size appropriate to the animal was then inserted with the help of a stylet in the bladder and the catheter balloon inflated with saline. Before inserting the catheter into the bladder it was passed through a subcutaneous tunnel made anterior to the incision. Normograde or retrograde flushing was not attempted. If the bladder was ruptured, urine and debris were removed from the bladder through the rupture, the rupture closed with 2 inverting layers of 0 or 2- 0 catgut, and the abdomen lavaged with warmed sterile saline that was aspirated using active suction. Partial cystectomy was not required in any animal. The abdomen was lavaged with warmed sterile saline and aspirated before 3-layer closure of the celiotomy. No attempt was made to occlude the open end of the Foley's catheter outside the body after surgery. In some cases, because of excessive catheter length, an abdominal bandage was placed and the catheter coiled somewhat to hold the end near the belly wall. After completion of clinical trial 5\% dextrose was administered, if required. The different treatments were evaluated on the basis of following parameters:

Clinical observations: All the clinical parameters were recorded before administration of the drug $(\mathrm{s})$ (baseline values) and then at 5, 10, 15, 20, 30, 45, 60, 75 and 90 minutes (Table-1). Induction dose ( $\mathrm{mg} / \mathrm{kg}$ ) and maintenance dose $(\mathrm{mg} / \mathrm{kg} / \mathrm{min})$ of propofol or ketamine were recorded in both groups. Recovery time was recorded as the time elapsed from discontinuation of injection of drugs to the reappearance of pedal reflex. Sternal recumbency time (SRT) was recorded as the time elapsed from discontinuation of injection of drugs until the spontaneous regaining of sternal recumbency. Standing time (ST) was recorded as the time elapsed from the time of discontinuation of injection of drugs until the spontaneous regaining of standing position and able to walk. Duration of anaesthesia was recorded as the time elapsed from the time of abolition of pedal reflex to the time of reappearance of pedal reflex.

Physiological observations: Heart rate (beats/min) by non-invasive blood pressure (NIBP) monitor, respiratory rate (breaths/min) by counting the movement of thorax and rectal temperature $\left({ }^{\circ} \mathrm{C}\right)$ by a digital thermometer were recorded before at 0 minute and at $5,10,15,20$, $30,45,60,75$, and 90 minutes after administration of drugs.

Haematobiochemical observations: Blood samples were collected from a separate drug sampling catheter in the jugular vein at $0 \mathrm{~min}$ (base line), 15,30, 60 and 90 minutes after administration of drugs (start of TIVA). Heparin (1:1000) and sodium fluoride (for glucose) were used for collection of plasma. The blood was 
Table-1: Numeric scoring system used for recording of various reflexes and responses.

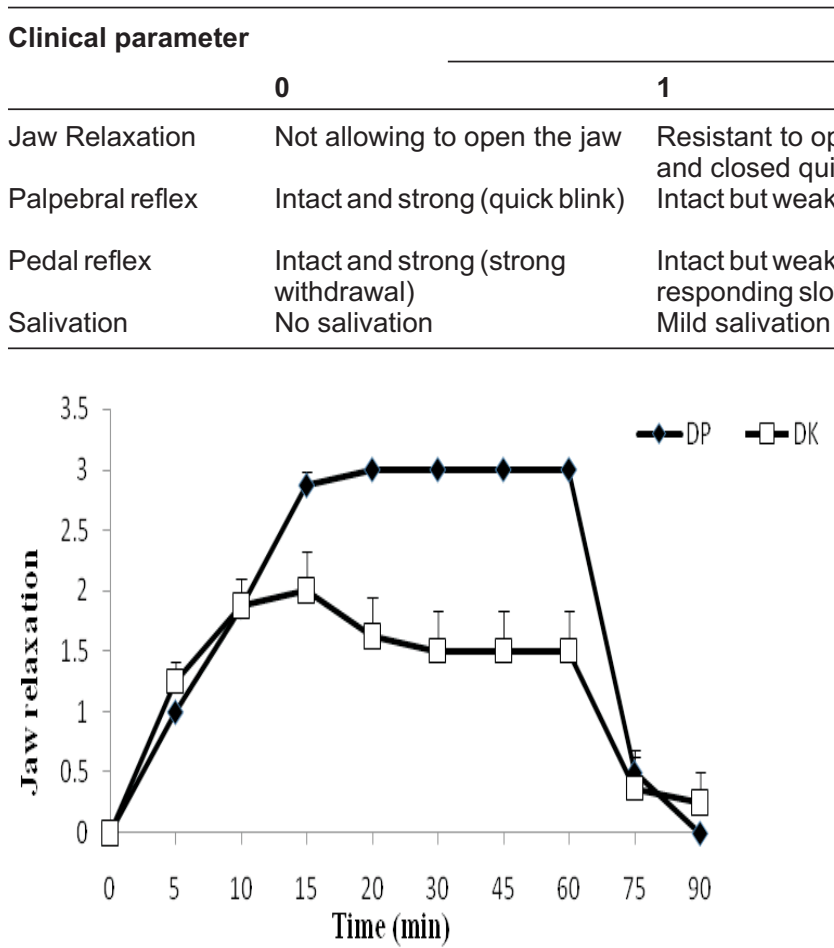

Figure-1: Mean \pm SE score for jaw relaxation in the animals of groups DP and DK at different time intervals.

immediately centrifuged at $850 \mathrm{~g}$ for six minutes and plasma was frozen at $-80^{\circ} \mathrm{C}$ until biochemical analysis. Haemoglobin $(\mathrm{Hb})$ was estimated by Sahli's haemoglobinometer and values were expressed in $\mathrm{g} / \mathrm{L}$. Packed cell volume (PCV) was estimated by microhaematocrit method and values were expressed in L/L. Total leukocyte count (TLC) was estimated by using Neubauer's counting chamber and values were expressed in $\mathrm{X} 10^{9} / \mathrm{L}$. For differential leukocyte count (DLC) a thin blood smear was prepared, stained and cells were counted by standard method and values were expressed in percent.

Plasma urea nitrogen $(\mathrm{mmol} / \mathrm{L})$ was estimated by diacetyl monoxide (DAM) method, plasma glucose (mmol/L) was estimated by GOD/POD method and plasma creatinine $(\mu \mathrm{mol} / \mathrm{L})$ was estimated by alkaline picrate method.

Haemodynamic observations: Systolic blood pressure (SBP), diastolic blood pressure (DBP) and mean arterial pressure (MAP) by non invasive blood pressure (NIBP) monitor and oxygen saturation of haemoglobin $\left(\mathrm{SpO}_{2}\right)$ by a pulse oxymeter were recorded after stabilization period at $0 \mathrm{~min}$ (base line) and at 5, 10, 15, 20, 30,45 and 60 minutes after administration of the drug.

Statistical analysis: One way ANOVA was used to compare the values of recovery time, sternal recumbency time and duration of anaesthesia between groups. Two-way ANOVA was used to compare the means at different time intervals among different groups as well as at different time intervals using Proc. GLM of SAS 9.2. The subjective data generated from the scoring of various parameters was analyzed using Kruskal Wallis

\section{Score}

2

No resistance and jaws remain open

Abolished the jaws and closed slowly Very weak (very slow and occasional) Intact but very light (slow and occasional response) Moderate salivation

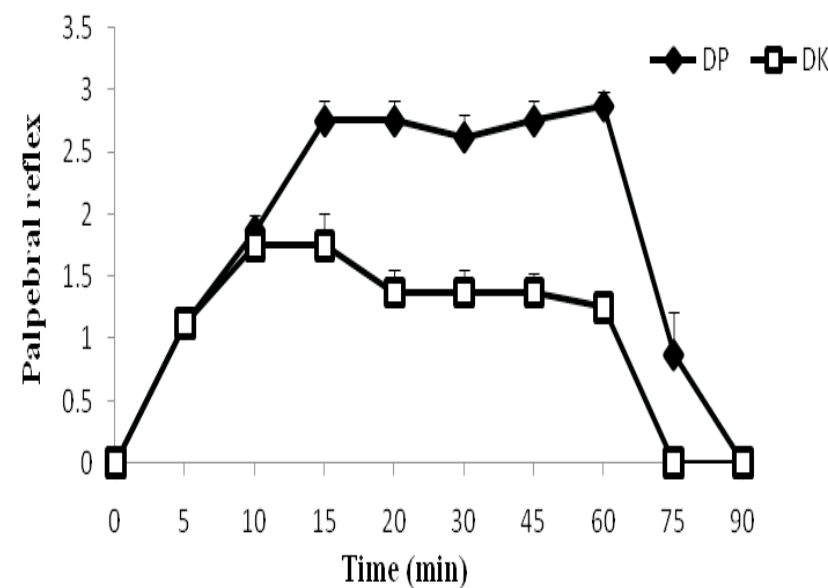

Figure-2: Mean \pm SE score for palpebral reflex in the animals of groups DP and DK at different time intervals.

test [10]. Statistical significance was assessed at $\mathrm{p}<$ 0.05 .

\section{Results}

Mild to moderate jaw relaxation was observed in all animals after premedication followed by excellent relaxation after induction in treatment DP however, jaws were mildly relaxed up to the end of anaesthetic period in DK (Figure-1). A mildly depressed palpebral reflex was recorded after premedication followed by moderately abolished reflex up to the end of anaesthesia in DP and a mildly depressed reflex in DK (Figure-2). A mildly depressed pedal reflex was recorded after premedication however, excellent depression of pedal reflex after induction of anaesthesia was observed in both groups up to the end of anaesthetic period (Figure-3). A very mild salivation was present in animals of both groups.

The median \pm SD values of recovery time recorded in groups DP and DK were $5.12 \pm 0.89 \mathrm{~min}$, $7.25 \pm 1.76$ min respectively (Figure-4). Group DP animals, recovered earlier than group DK. The recovery time however, did not differ significantly $(\mathrm{p}>0.05)$. The median \pm SD of sternal recumbency time recorded in groups DP and DK were $13.00 \pm 1.56 \mathrm{~min}$ and 21.37 \pm 2.46 min respectively (Figure-4). Group DK animals took significantly $(p<0.05)$ longer time to resume sternal recumbency than group DP. Standing time in group DK $(40.50 \pm 4.68 \mathrm{~min})$ was significantly $(\mathrm{p}<$ $0.05)$ longer than in group DP $(19.75 \pm 2.57 \mathrm{~min})$.

The mean values of induction and maintenance dose of propofol and ketamine recorded in groups DP and DK were $2.50 \pm 0.37 \mathrm{mg} / \mathrm{kg}$ and $9.85 \pm 0.85 \mathrm{mg} / \mathrm{kg} \&$ 


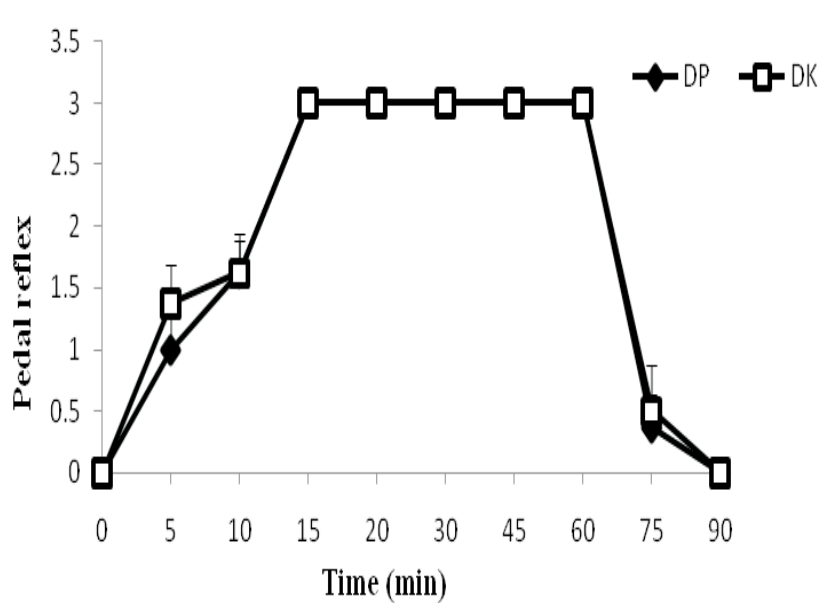

Figure-3: Mean \pm SE score for pedal reflex in the animals of groups DP and DK at different time intervals.

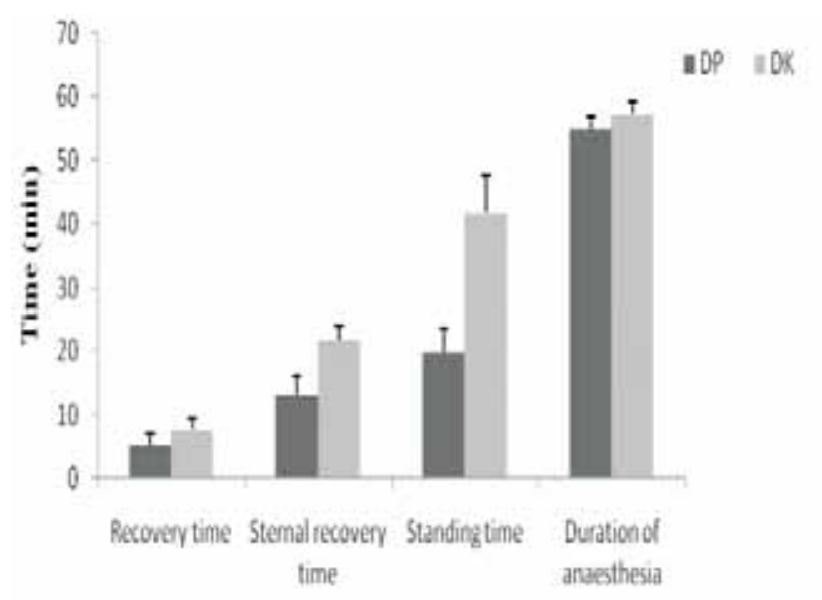

Figure-4: Median \pm SD values of recovery time, sternal recovery time, standing time and duration of anaesthesia in the animals of groups DP and DK.

Table-2: Mean \pm SE of HR, RR, RT \& MAP values obtained before treatment (baseline), immediately after sedation (sedation) and during anaesthesia.

\begin{tabular}{|c|c|c|c|c|c|}
\hline Time (min.) & Treatment & HR & $\mathbf{R R}$ & RT & MAP \\
\hline \multirow[t]{2}{*}{0 Baseline } & $\mathrm{DP}$ & $118.75^{\mathrm{abcA}} \pm 12.78$ & $32.75^{\mathrm{aA}} \pm 1.13$ & $38.14^{\mathrm{abA}} \pm 0.51$ & $119.50^{\mathrm{A}} \pm 4.59$ \\
\hline & DK & $130.75^{\mathrm{acA}} \pm 11.47$ & $38.38^{\mathrm{abAC}} \pm 1.87$ & $36.69^{\mathrm{bA}} \pm 0.37$ & $123.00^{\mathrm{A}} \pm 5.75$ \\
\hline \multirow[t]{2}{*}{5} & $\mathrm{DP}$ & $90.62^{\mathrm{abB}} \pm 6.01$ & $21.25^{\mathrm{BC}} \pm 2.53$ & $37.69^{\mathrm{bAC}} \pm 0.57$ & $97.50^{\mathrm{B}} \pm 4.11$ \\
\hline & DK & $96.62^{\mathrm{bBC}} \pm 7.76$ & $26.00^{\mathrm{B}} \pm 1.19$ & $38.21^{\mathrm{bAC}} \pm 0.32$ & $107.38^{\mathrm{AB}} \pm 6.01$ \\
\hline \multirow[t]{2}{*}{10 Induction } & $\mathrm{DP}$ & $91.75^{\mathrm{acB}} \pm 2.45$ & $20.00^{\mathrm{aBC}} \pm 1.85$ & $37.69^{\mathrm{bAC}} \pm 0.54$ & $88.75^{\mathrm{B}} \pm 5.52$ \\
\hline & DK & $87.50^{\mathrm{cC}} \pm 6.40$ & $33.50^{\mathrm{bcc}} \pm 1.88$ & $38.10^{\mathrm{bAC}} \pm 0.31$ & $98.25^{\mathrm{BC}} \pm 5.06$ \\
\hline \multirow[t]{2}{*}{15} & DP & $91.75^{\mathrm{B}} \pm 1.73$ & $18.25^{\mathrm{aB}} \pm 1.85$ & $37.45^{\mathrm{abAD}} \pm 0.56$ & $81.75^{\mathrm{aB}} \pm 7.03$ \\
\hline & DK & $93.75^{\mathrm{BC}} \pm 3.37$ & $39.25^{\mathrm{bA}} \pm 2.26$ & $37.47^{\mathrm{abAD}} \pm 0.37$ & $105.25^{\mathrm{bAC}} \pm 4.70$ \\
\hline \multirow[t]{2}{*}{20} & $\mathrm{DP}$ & $89.50^{B} \pm 2.38$ & $19.25^{\mathrm{aB}} \pm 1.69$ & $37.33^{\mathrm{bACD}} \pm 0.49$ & $83.25^{\mathrm{aB}} \pm 7.47$ \\
\hline & DK & $95.00^{\mathrm{BC}} \pm 4.12$ & $38.00^{\mathrm{CAC}} \pm 1.46$ & $37.22^{\mathrm{bCD}} \pm 0.38$ & $116.88^{\mathrm{bA}} \pm 7.36$ \\
\hline \multirow[t]{2}{*}{30} & $\mathrm{DP}$ & $92.62^{B} \pm 3.06$ & $22.25^{\mathrm{aBC}} \pm 1.53$ & $36.89^{\mathrm{CD}} \pm 0.48$ & $86.00^{\mathrm{aB}} \pm 6.39$ \\
\hline & DK & $101.25^{\mathrm{BC}} \pm 4.66$ & $37.25^{\mathrm{bAC}} \pm 1.73$ & $36.74^{\mathrm{DE}} \pm 0.39$ & $115.12^{\mathrm{bAC}} \pm 7.19$ \\
\hline \multirow[t]{2}{*}{45} & $\mathrm{DP}$ & $97.75^{\mathrm{B}} \pm 3.25$ & $24.87^{\mathrm{aC}} \pm 1.41$ & $36.25^{\mathrm{D}} \pm 0.59$ & $85.75^{\mathrm{aB}} \pm 7.00$ \\
\hline & DK & $96.50^{\mathrm{BC}} \pm 4.24$ & $36.62^{\mathrm{bAC}} \pm 1.95$ & $36.01^{E} \pm 0.47$ & $116.50^{\mathrm{bA}} \pm 4.88$ \\
\hline \multirow[t]{2}{*}{60} & DP & $98.87^{\mathrm{B}} \pm 4.62$ & $28.50^{\mathrm{aAC}} \pm 2.19$ & $35.96^{\mathrm{BCD}} \pm 0.52$ & $85.62^{\mathrm{aB}} \pm 7.65$ \\
\hline & DK & $105.88^{B} \pm 6.86$ & $35.75^{\mathrm{bAC}} \pm 1.44$ & $35.67^{\mathrm{BE}} \pm 0.27$ & $120.50^{\mathrm{bA}} \pm 5.53$ \\
\hline \multirow[t]{2}{*}{75} & DP & $100.38^{\mathrm{B}} \pm 5.45$ & $27.87^{\mathrm{aAC}} \pm 2.00$ & $35.71^{\mathrm{BD}} \pm 0.54$ & - \\
\hline & DK & $104.75^{\mathrm{BC}} \pm 3.91$ & $33.25^{\mathrm{bAC}} \pm 1.06$ & $35.23^{\mathrm{B}} \pm 0.29$ & - \\
\hline \multirow[t]{2}{*}{90} & $\mathrm{DP}$ & $103.75^{\mathrm{A}} \pm 5.03$ & $29.50^{\mathrm{aAC}} \pm 1.55$ & $35.68^{\mathrm{BCD}} \pm 0.53$ & - \\
\hline & DK & $114.00^{\mathrm{BC}} \pm 5.43$ & $35.50^{\mathrm{bAC}} \pm 0.98$ & $35.23^{B} \pm 0.27$ & - \\
\hline
\end{tabular}

Means with different upper superscript within a group differ significantly $(p<0.05)$. Means with different lower superscript between groups differ significantly $(p<0.05)$.

$0.15 \pm 0.03 \mathrm{mg} / \mathrm{kg} / \mathrm{min}$ and $0.54 \pm 0.07 \mathrm{mg} / \mathrm{kg} / \mathrm{min}$ respectively.

Heart rate decreased gradually but remained significantly $(\mathrm{p}<0.05)$ lower than the baseline value until the end of observation period in both groups (Table-2). Respiratory rate decreased significantly $(\mathrm{p}<0.05)$ after premedication with dexmedetomidine (Figure-6). The RR continued to decrease significantly $(\mathrm{p}<0.05)$ lower than the baseline after induction of anaesthesia up to $45 \mathrm{~min}$ in DP (Table-2). However, after induction of anaesthesia with ketamine respiratory rate decreased significantly $(\mathrm{p}<0.05)$ only at 15 min thereafter, values were non-significantly $(p>0.05)$ lower than the baseline value up to the end of observation period. Comparison between both groups revealed that the mean respiratory rate was significantly $(\mathrm{p}<$
$0.05)$ lower at $10 \mathrm{~min}$ and onwards up to the end of observation period in DP. RT decreased non-significantly $(\mathrm{p}<0.05)$ after premedication with dexmedetomidine (Table-2). However, after induction of anaesthesia RT decreased significantly $(p<0.05)$ at most of the intervals up to the end of observation period in both groups (Figure-7).

Haemoglobin values did not differ significantly from the respective base values throughout the observation period in both groups. A significant $(p<0.05)$ decrease in PCV and TLC was recorded at most of the time intervals as compared to base value in DP. A nonsignificant $(\mathrm{p}>0.05)$ increase in neutrophil count was recorded at most of the time intervals interval in both groups.

Plasma urea nitrogen and plasma glucose 


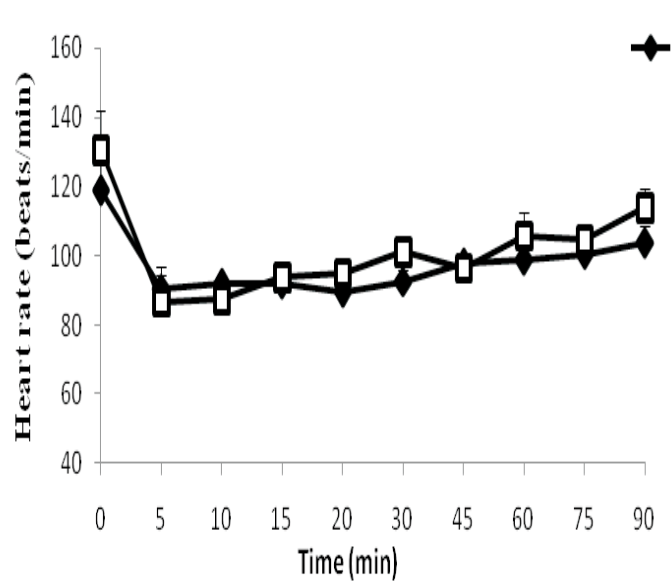

Figure-5: Mean \pm SE values of Heart rate in the animals of groups DP and DK at different time intervals.

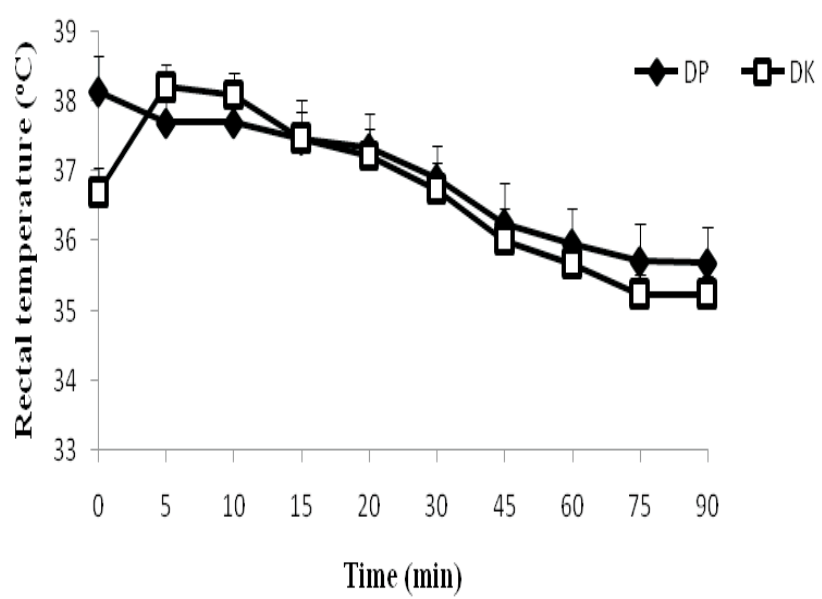

Figure-7: Mean \pm SE values of rectal temperature in the animals of groups DP and DK at different time intervals.

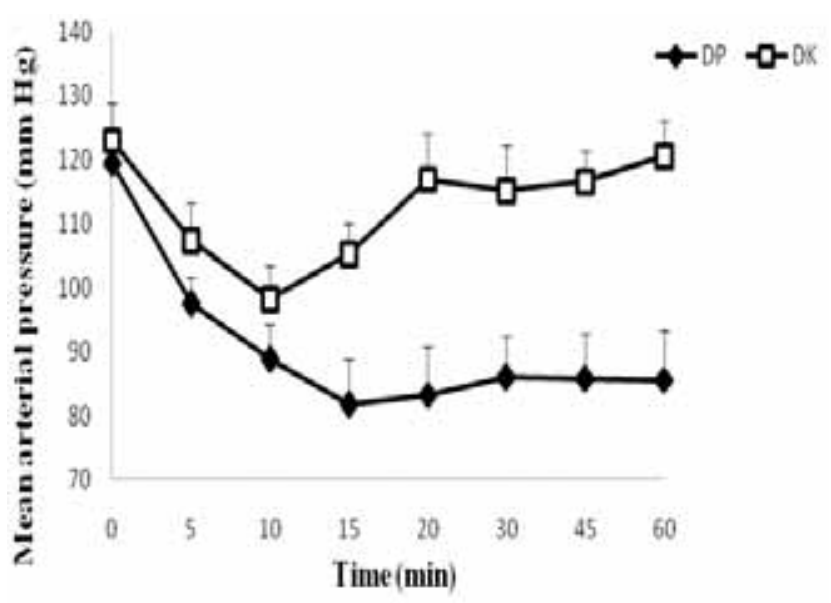

Figure-9: Mean \pm SE values of mean arterial pressure in the animals of groups DP and DK at different time intervals.

increased non-significantly $(\mathrm{p}>0.05)$ up to the end of observation period however, plasma creatinine nonsignificantly $(p>0.05)$ fluctuated near the baseline in both groups.

$\mathrm{SpO}_{2}$ values were non-significantly ( $\left.\mathrm{p}>0.05\right)$ higher in DK than DP at most of the intervals (Figure-8). Mean arterial pressure (MAP) decreased significantly $(\mathrm{p}<0.05)$ after premedication and induction of anaesthesia in both groups however, MAP improved at $15 \mathrm{~min}$ and

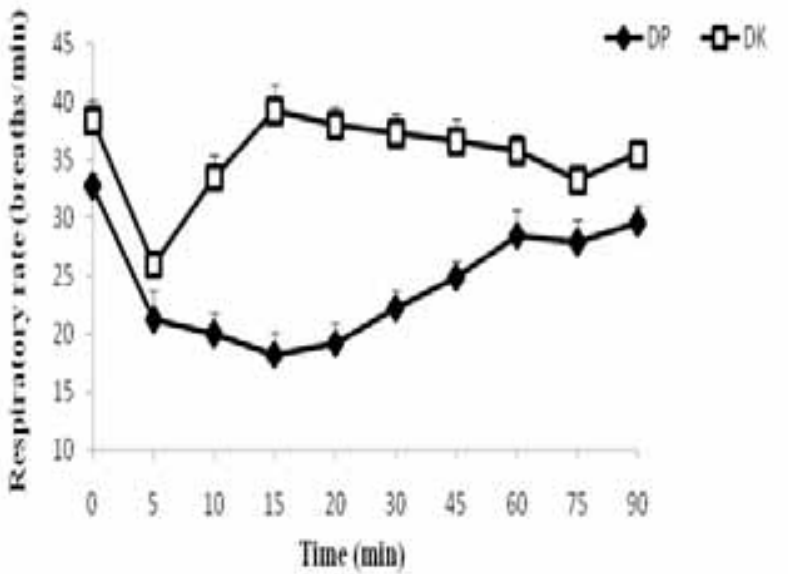

Figure-6: Mean $\pm S E$ values of respiratory rate in the animals of groups DP and DK at different time intervals.

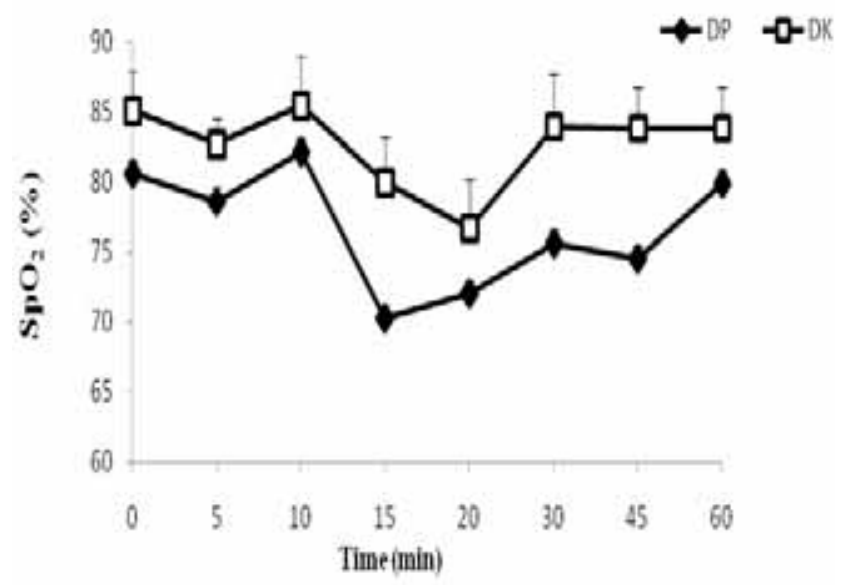

Figure-8: Mean $\pm S E$ values of oxygen saturation of haemoglobin $\left(\mathrm{SpO}_{2}\right)$ in the animals of groups DP and DK at different time intervals.

onwards in DK (Figure-9). MAP in propofol group was significantly $(\mathrm{p}<0.05)$ lower than that in ketamine group at 15, 20,30, 45 and $60 \mathrm{~min}$ (Table-2).

It was found that goats have a better prognosis after tube cystostomy than other animals, no fluid in the abdomen, and no urethral process amputation before admission were associated with improved survival. Unexpectedly, age at castration did not affect outcome. Castrated males were more likely to survive, but this finding was not statistically significant. It was normally recommend discontinuing or markedly reducing grain feeding, increased grazing, and a change from green grass-to-grass hay at discharge, as well as feeding ammonium chloride.

\section{Discussion}

Adequate muscle relaxation was reported in medetomidine-butorphanol and acepromazine-butorphanol premedicated buffaloes after induction with thiopental and propofol [11]. Ketamine does not have muscle relaxant property and relaxation of jaw in animals of both groups might be attributed to the action of dexmedetomidine.

Higher degrees of abolished palpebral reflex have been reported following administration of dexmedeto- 
midine-butorphanol-midazolam in sheep undergoing propofol anaesthesia [8]. However, palpebral, corneal and swallowing reflexes have been reported to be mildly active during ketamine anaesthesia in goats [12] and buffaloes [6]. Similarly, sluggish palpebral reflex has also been reported following premedication with pentazocine alone or in combination with chloramphenicol for propofol anaesthesia in dogs [13]. Similar findings have been reported in the present study.

Anaesthesia with propofol has been successfully induced after premedication with $\alpha_{2}$-agonists [7] and midazolam in dogs [14]. In the present study also dexmedetomidine helped in producing better induction with propofol and subsequent maintenance of anaesthesia. Ketamine is a general anaesthetic and its anaesthetic action is produced by interruption of ascending transmission from those parts of the brain responsible for unconscious and conscious functions [15]. Ketamine possesses potent analgesic property but propofol is thought to have no or minimal intrinsic analgesic property [15].

Mild degree of salivation after induction with either propofol or ketamine in the present study might be due to delayed effect of $\alpha_{2}$-agonists, dexmedetomidine or due to decreased swallowing reflex. Similarly, mild degree of salivation has also been reported after administration of medetomidine or dexmedetomidine along with butorphanol or midazolam in sheep undergoing propofol anaesthesia [8] and in buffaloes under ketamine maintenance of anaesthesia [6].

Lower RT, SRT and ST in propofol anaesthesia might be due to virtual lack of any cumulative effect either by repeat bolus injection or by continuous infusion [16]. Propofol is an ultra-short acting drug and distribution and elimination of propofol are rapid after bolus injection or after constant infusion [17] our findings supported the observations.

Increase in HR after administration of propofol might be due to increase in the myocardial blood flow, stimulation of cardio excitatory center of brain or stimulation of sympathetic nervous system or positive chronotropic effect of propofol [15]. Higher values of heart rate during ketamine infusion in comparison to post-sedation values in the present study could be attributed to its sympathomimetic action mediated within the CNS, inhibition of catecholamine re-uptake by peripheral sympathetic nerve endings and the subsequent effects of catecholamines on the myocardium [5].

Reduced RR has been reported following dexmedetomidine premedication in sheep [11]. Propofol caused a further decrease in mean RR by depressing central inspiratory drive and ventilatory response to arterial carbon-dioxide response [18]. Increase in respiratory rate recorded during induction and maintenance of anaesthesia with ketamine may be due to some degree of hyperventilation induced by ketamine. Similar observations have been reported in calves [6].

$\alpha_{2}$-agonists have been reported to induce prolonged depression of thermoregulation [19] and depress hypothalamic noradrenergic $\alpha_{2}$ adrenergic receptors to cause hypothermia [20]. Decrease in RT has been reported after medetomidine administration in goats [21] and sheep [11].

Induction dose of propofol $(4 \mathrm{mg} / \mathrm{kg})$ and for ketamine (11 to $22 \mathrm{mg} / \mathrm{kg}$ with atropine and xylazine premedication) in healthy goats has been reported [15]. In present study reduced induction dose of propofol and ketamine might be due to combined effect of increased urea nitrogen and creatinine.

Pooling of circulatory blood cells in the spleen or other reservoirs secondary to decreased sympathetic activity may explain the decrease in Hb, PCV and TLC recorded in the present study [22]. The decrease in PCV and $\mathrm{Hb}$ during the period of anaesthesia or sedation may be due to shifting of fluid from extravascular compartment to intravascular compartment in order to maintain normal cardiac output in animals [23]. The decreased $\mathrm{Hb}$ and PCV in the present study have also been reported after administration of medetomidine in goats [23], buffalo calves [24] and sheep [8], or along with butorphanol in buffaloes [6], butorphanol along with medetomidine in dogs or along with dexmedetomidine in sheep [8]. Neutrophilia and lymphocytopenia observed in the present study might be due to stress caused by the preanaesthetic and anaesthetic drugs and subsequent stimulation of adrenal glands.

Plasma urea nitrogen $(4.5$ to $10 \mathrm{mmol} / \mathrm{L})$ was slightly increased however, creatinine values ( 79.56 to $159 \mu \mathrm{mol} / \mathrm{L}$ ) were found to be two to three folds higher than the normal [1]. The increase in urea nitrogen might be attributed to temporary inhibitory effects of anaesthetic drugs on the renal blood flow, which in turn might have caused a rise in plasma urea nitrogen level [21]. A non-significant increase in blood urea nitrogen has been reported following use of midazolam-propofol [25] and midazolam-dexmedetomidine in dogs [26]. The increase in plasma glucose observed in the present study might be attributed to an $\alpha_{2}$-adrenergic inhibition of insulin release from beta cells of pancreas and increased glucose production in the liver [27]. Hyperglycemia may also be attributed to the traumatic stress or increased muscular activity and sympathetic stimulation caused by restraining the animals resulting into increased secretion of adrenocortical hormones [28]. A significant increase in glucose level was reported in dogs under pentazocine-propofol anaesthesia [13]. Increase in plasma glucose after medetomidine and medetomidineketamine administration has been reported in goats [21]. Plasma creatinine fluctuated non-significantly in both groups up to the end of study period and values were maintained near the baseline. Creatinine was reported to increase non-significantly following administration of butorphanol along with xylazine or medetomidine [28]. A non-significant change in creatinine was recorded after pentazocine-propofol anaesthesia [13] in buffalo calves.

The changes in $\mathrm{SpO}_{2}$ during propofol and ketamine 
infusion were inversely proportional to the rate of administration of drugs and could be adjusted easily by changing the rate of infusion. Ketamine infusion has been reported to cause significant respiratory depression with decrease in all measures of ventilation in animals [29] decreased $\mathrm{SpO}_{2}$ values have been reported following administration of butorphanol along with medetomidine or dexmedetomidine in propofol anaesthetized dogs [7] and sheep [8].

A decrease in blood pressure after propofol administration has been reported in goats [30], domestic animals and has been associated with arterial and venous vasodilatation and decreased contractility of the heart [31]. An increase in the arterial blood pressure after ketamine administration could be due to the selective positive inotropic influence on heart muscles or reflexogenic autonomic nervous system changes [32].

\section{Conclusion}

It can be concluded that after premedication with dexmedetomidine, a surgical plane of anaesthesia was recorded with propofol $(0.15 \pm 0.03 \mathrm{mg} / \mathrm{kg} / \mathrm{min})$ and ketamine $(0.54 \pm 0.07 \mathrm{mg} / \mathrm{kg} / \mathrm{min})$ TIVAs for one $\mathrm{h}$. Both treatments were suitable for producing excellent degree of analgesia. Ketamine TIVA was associated with better haemodynamic stability in comparison topropofol TIVA however; propofol treatment had advantage of excellent sedation and muscle relaxation.

\section{Authors' contributions}

RK, PK, A, HPA and AMP designed the study. RK, JS, SK and DNM performed the study. AK analyzed and interpreted the data. All authors participated in draft and revision of the manuscript. All authors read and approved the final manuscript.

\section{Acknowledgements}

The financial support and facilities provided by the Indian Veterinary Research Institute, Izatnagar, India are duly acknowledged.

\section{Competing interests}

The authors declare that they have no competing interests.

\section{References}

1. Radostits, O.M., Gay, C.C., Hinchkliff, K.W. and Constable, P.D. (2007) Veterinary Medicine. $10^{\text {th }}$ ed. Bailliere Tindall, London.

2. Bidwell, L.A., Bramlage, L.R., and Rood, W.A. (2007) Equine perioperative fatalities associated with general anaesthesia at a private practice-a retrospective case series. Vet. Anaesth. Analg., 34:23-30.

3. McKenzi, G. (2008) Total intravenous anesthesia - TIVA. Iran J Vet Surg., 2: 108-117.

4. Steffey, E.P. (2002) Recent advances in inhalation anesthesia. Vet. Clin. North Am. Equine Pract., 18: 159-168.

5. Hayashi, Y., Sumikawa, K., Maze, M., Yamatodani, A., Kamibayashi, T., Kuro, M. and Yoshiya, I. (1991) Dexmedetomidine prevents epinephrine induced arrhythmias through stimulation of central alpha-2-adrenoceptors in halothane-anesthetized dogs. Anesthesiol., 75: 113-117.

6. Malik, V., Kinjavdekar, P., Amarpal, Aithal, H.P., Pawde,
A.M. and Surbhi (2011) Sedative, analgesic, cardiopulmonary and haemodynamic effects of medetomidinebutorphanol and midazolam-butorphanol on thiopentalpropofol anaesthesia in water buffaloes (Bubalus bubalis). $J$. App. Anim. Res., 39:284-287.

7. Gupta, A. N. (2010) Evaluation of medetomidine and dexmedetomidine with propofol for TIVA and tramadol and fentanyl for analgesic management of canine orthopaedic patients. M.V.Sc. Thesis submitted to Deemed University, Indian Veterinary Research Institute, Izatnagar, (U.P.), India.

8. Monsang, S.W. (2011) Comparison of medetomidine and dexmedetomidine with and without butorphanol and midazolam as preanaesthetics to propofol Anaesthesia in sheep. M.V.Sc Thesis submitted to Deemed University, Indian Veterinary Research Institute, Izatnagar, (U.P.), India.

9. Amarpal, Kinjavdekar, P., Aithal, H.P., Pawde, A.M. and Pratap, K. (2002) Analgesic, sedative and haemodynamic effects of spinally administered romifidine in female goats. J. Vet. Med. A Physiol. Pathol. Clin. Med., 49:3-8.

10. Snedecor, G.W. and Cochran, W.G. (1980) Statistical methods. $9^{\text {th }}$ ed., Iowa State University, Press.

11. Ahmad, R. (2009) Evaluation of halothane anaesthesia following induction with propofol or thiopental in acepromazine/medetomidine-butorphanol premedicated buffaloes. M.V.Sc. Thesis submitted to Deemed University, Indian Veterinary Research Institute, Izatnagar, (U.P.), India.

12. Tadmor, A. and Zukerman, I. (1981) The use of ketamine HCL for endotracheal intubation in goats. Aust. Vet. J., 57: 303-304.

13. Chandrashekarappa, M. and Ananda, K.J. (2009) Evaluation of anaesthetic combinations of propofol with pentazocine lactate and chloramphenicol in dogs. Indian Vet. J., 86: 577579.

14. Rafee, M.A. (2013) Evaluation of midazolam and ketamine anaesthesia for ovariohysterectomy in dexmedetomidine with or without butorphanol/pentazocine premedicated dogs. M.V.Sc. Thesis submitted to Deemed University, Indian Veterinary Research Institute, Izatnagar, (U.P.), India.

15. Tranquilli, W.J., Thurmon, J.C and Grimm, K.A. (2007) In: Veterinary Anaesthesia and Analgesia. $4^{\text {th }}$ ed. Blackwell Publishing Ltd., Iowa, USA.

16. Adetunji, A., Ajadi, R.A., Adewoye, C.O. and Oyemakinde, B.O. (2002) Total intravenous anaesthesia with propofol: Repeat bolus versus continuous propofol infusion techniques in xylazine premedicated dogs. J. Israel Vet. Med. Assoc., 57: 139-144.

17. Gepts, E., Camu, F. and Cockshott, I.D. (1987) Disposition of propofol administered as constant rate infusion in human. Anaesth. Analg., 66: 1256-1263.

18. Singh, J. (2013) Evaluation of isoflurane anaesthesia in premedicated buffaloes. PhD Thesis submitted to Deemed University, Indian Veterinary Research Institute, Izatnagar, (U.P.), India.

19. Ponder, S.W. and Clarke, W.G. (1980) Prolonged depression of thermoregulation after xylazine administration to cats. $J$. Vet. Pharmacol. Therap., 3:203-207.

20. MacDonald, E., Scheinin, H. and Schienin, M. (1988) Behavioural and neurological effects of medetomidine, a novel veterinary sedative. European J. Pharmacol., 158: 119-127.

21. Kinjavdekar, P., Singh, G.R., Amarpal, Aithal, H.P. and Pawde, A.M. (2000) Physiologic and biochemical effects of subarachnoidally administered xylazine and medetomidine in goats. Small Rum. Res., 38:217-228.

22. Wagner, A.E., Muir, W.W. and Hinchcliff, K.W. (1991) Cardiovascular effects of xylazine and detomidine in horses. Am.J. Vet. Res., 52: 651-657.

23. Kinjavdekar, P., Singh, G.R., Amarpal, Pawde, A.M., Aithal, H.P. (1999) Effects of subarachnoid xylazine and medetomidine on haemodynamic and ECG in goats. J. Vet. Med.Assoc., 46: 271-272.

24. Pratap, K., Amarpal, Kinjavdekar, P. and Singh, G.R. (2000) 
Effects of medetomidine alone or in combination with ketamine on analgesia, physiological parameters and blood values of buffalo calves (Bubalus bubalis). Phillip. J. Vet. Med., 37:38-40.

25. Khan, K.M., Mehesare, S.P., Pawshe, D.B., Patil, R.B. and Rahman, S. (2006) Effect of midazolam as preanaesthetic to propofol anaesthesia in canine on haematological and biochemical parameters. Vet. World., 5(3): 77-80.

26. Santhosh, K. M. (2011). Evaluation of dexmedetomidine as preanaesthetic to ketamine anaesthesia in midazolam or midazolam-fentanyl premedicated dogs. M.V.Sc. Thesis submitted to Deemed University, Indian Veterinary Research Institute, Izatnagar, (U.P.), India.

27. Surbhi, Kinjavdekar, P., Amarpal, Aithal, H.P., Pawde, A.M., Pathak, M. C., Borena, B.M. and Malik, V. (2010) Physiological and biochemical effects of medetomidinebutorphanol-propofol anaesthesia in dogs undergoing orthopaedic surgery. Indian J. Vet. Surg., 31: 101-104.

28. Gasthuys, F., Terpstra, P., Hende, C.V. and DeMoor, A.
(1987) Hyperglycemia and diuresis during sedation with detomidine in the horse. J. Am. Vet. Med. Assoc., 34: 641.

29. Singh, G.D. (2011) Comparative evaluation of halothane and isoflurane inhalation anaesthesia in buffaloes. Ph.D. Thesis submitted to Deemed University, Indian Veterinary Research Institute, Izatnagar, (U.P.), India.

30. Dzikiti, T.B., Stegmen, G.F., Dzikiti, L.N. and Hellebrekers, L.J. (2010) Total intravenous ananesthesia (TIVA) with propofol-fentanyl and propofol-midazolam combinations in spontaneously breathing goats. Anaesth. Analg., 37: 519-525.

31. Kuusela, E., Vainio, O., Short, C.E., Leppaluoto, J., Huttunen, P., Strom, S., Huju, V., Valtonen, A. and Raekallio, M. (2003) A comparison of propofol infusion and propofol isoflurane anaesthesia in dexmedetomidine premedicated dogs. J. Vet. Pharmacol. Therap., 26:199-204.

32. Ilkiw, J.E., Pascoe, P.J., Haskins, S.C. and Patz, J.D. (1992) Cardiovascular and respiratory effects of propofol administration in hypovolaemic dogs. Am. J. Vet. Res., 53: 2323-2327.

$* * * * * * * *$ 